\title{
Marking the status and development of marine VOCs recovery technology
}

\author{
Guo Ting ${ }^{1}$, Jiao Yuang ${ }^{1}$, Tang Yanbing ${ }^{1}$, Lu Daohua $^{1}$, Kong Xianglei ${ }^{1}$, Shen Jiubing ${ }^{1}$, Jiang Qingfeng ${ }^{1}$ \\ ${ }^{1}$ Jiangsu University of science and technology College of energy and power
}

\begin{abstract}
During the storage and transportation of crude oil, volatile organic vapors (VOCs) are generated. International organizations and relevant countries have formulated relevant regulations for VOCs emissions. This article introduces four kinds of oil and gas recovery technologies and their combined processes: absorption method, adsorption method, membrane separation method and condensation method. The advantages and disadvantages of different oil and gas recovery technologies are analyzed and the process performance is compared. It lists examples of the application of oil and gas recovery technology in ships, points out its shortcomings, and puts forward relevant suggestions for the research of marine VOCs recovery technology.
\end{abstract}

\section{Introduction}

During the loading,transportation, and unloading of crude oil, VOCs (volatile organic compounds) will volatilize from the oil. The International Maritime Organization approved in 1997 the rules for preventing air pollution from ships to join the "MARPOL 73/78 Convention on Pollution Prevention" and entered into force in 2005.Countries around the world have also taken corresponding measures to prevent pollution caused by ships' oil and gas. In the last century, many countries in the United States and Europe have required oil and gas recovery systems to be installed on incoming tankers, and oil and gas recovery devices at the tanker docks. The promulgation and implementation of the "Regulations on the Prevention and Control of Marine Environmental Pollution by Ships" by the State Council of my country in 2009 and the entry into force of MARPOL 73/78 in my country opened up my country's enhanced management of oil and gas emissions. The "Technical Regulations for the Statutory Inspection of Domestic Navigational Sea Vessels (2020)" stipulates: For domestic navigational oil tankers of 150 gross tonnage and above built on or after January 1, 2020, entering the ship's emission control area, they should be equipped with Approved steam emission collection system $^{[1]}$.

\section{The necessity of oil and gas recovery technology}

2.1 Oil and gas are non-renewable resources and have a certain degree of volatility. If they are not controlled, it will cause great energy loss and resource waste, and cause serious economic losses to oil companies. Oil and gas recovery technology is a technology that petroleum companies have to master. It not only improves the economic benefits of the company, but also responds to the national development concept of green environmental protection, energy saving and emission reduction.

\subsection{The evaporation of oil and gas will emit a} large amount of harmful gases, causing serious pollution to the environment or the greenhouse effect. At present, environmental protection issues have received global attention, and the concept of sustainable development has been recognized globally. Countries and regions have promulgated a series of environmental protection laws and standards, which have made stricter requirements for environmental protection, and ensure the construction of ecological civilization while developing. Respond to the leadership of the party and the country, promote environmental protection and green life, and build a beautiful new China in an all-round way.

2.3 During the process of production, storage and transportation of oil products, a large amount of harmful gases are emitted. When the concentration of the emitted gas is too high and the staff stays in this environment for a long time, it will cause harm to the human body, resulting in dizziness, vomiting and other symptoms, or even possible Causes various diseases such as poisoning and disease. At the same time, the vaporized components of oil and gas are flammable. When the concentration reaches a certain level, it will explode when exposed to open flames or static electricity. Oil and gas recovery technology can solve various hidden dangers and risks, ensure that the discharged gas is safe, ensure the safety of 
personnel, and avoid accidents.

\section{Oil and gas recovery technology}

At present, there are four common oil and gas recovery technologies at home and abroad: absorption method; adsorption method; membrane separation method; condensation method.

\subsection{Absorption method}

Absorbed oil and gas recovery technology is based on pressure and temperature, divided according to temperature, there are mainly normal temperature and pressure absorption method and normal pressure and low temperature absorption method ${ }^{[2]}$. The principle is to use the different solubility of the oil-gas mixture in the absorbent to realize the separation of hydrocarbon components from air.

Atmospheric low-temperature recovery technology requires the use of coolant to control the absorbent at a lower temperature, generally at $-30^{\circ} \mathrm{C}$. Absorbent is the key to the absorption method of oil and gas recovery technology. The conditions to be met are: good solubility for oil and gas, absorption, non-toxic, non-flammable, hard to volatile, and good chemical stability. However, it is difficult for general absorbents to meet all the conditions. For different volatile gases, it is necessary to select a suitable dissolving agent to achieve a better absorption effect.

\subsection{Adsorption method}

Adsorption oil and gas recovery technology uses adsorbents to have a certain degree of adsorption to oil and gas components, that is, there is a gap between the binding strength of the adsorbent and each component, so that it can be separated from natural gas, thereby eliminating harmful gases. Activated carbon is the most commonly used adsorption material, and its adsorption capacity for hydrocarbons can reach $34 \%{ }^{[4]}$.

The key factors affecting the adsorption method:

1) High-quality and high-performance adsorbent;

2) Optimize the key components of the recovery device;

3) The best process parameters (such as temperature,

Table 2. Advantages and disadvantages of oil and gas recovery technology

\begin{tabular}{|c|c|c|c|}
\hline Method & Advantage & Disadvantage & Key research \\
\hline $\begin{array}{l}\text { Absorpti } \\
\text { on } \\
\text { method }\end{array}$ & $\begin{array}{l}\text { Adaptation and treatment of high } \\
\text { concentration and large flow oil } \\
\text { and gas }\end{array}$ & $\begin{array}{l}\text { Need to be equipped with a heating } \\
\text { analysis and recovery device, the } \\
\text { equipment is large, when the } \\
\text { concentration of oil and gas emissions is } \\
\text { very low, the cost will increase sharply }\end{array}$ & $\begin{array}{l}\text { Development of special } \\
\text { absorbents, optimization and } \\
\text { miniaturization of important } \\
\text { devices, etc. }\end{array}$ \\
\hline $\begin{array}{l}\text { Activated } \\
\text { carbon } \\
\text { adsorptio } \\
\mathrm{n} \text { method }\end{array}$ & $\begin{array}{l}\text { Excellent adsorption performance, } \\
\text { easy to desorb, little change in } \\
\text { performance after repeated } \\
\text { adsorption and desorption, not } \\
\text { easy to crack, easy to manufacture, } \\
\text { low price, wide range of use, high } \\
\text { economic efficiency, suitable for }\end{array}$ & $\begin{array}{l}\text { When the intake air concentration is too } \\
\text { large, the adsorption capacity will } \\
\text { decrease, which may cause the activated } \\
\text { carbon to spontaneously ignite; secondary } \\
\text { pollution will be generated during the } \\
\text { analysis process }\end{array}$ & $\begin{array}{l}\text { Improve the effective aperture } \\
\text { ratio of activated carbon, reduce } \\
\text { the adsorption attenuation of } \\
\text { activated carbon after multiple } \\
\text { adsorption, and reduce the } \\
\text { deterioration of activated carbon } \\
\text { performance due to adsorption }\end{array}$ \\
\hline
\end{tabular}

\subsection{Membrane separation method}

Separation membranes made of special technology and special materials have different permeability to oil and gas mixed gases, and the hydrocarbon components have the characteristics of preferential permeability in the polymer membrane. Under certain pressure, the oil and gas molecules can pass through preferentially. Separation membrane to realize the separation of oil and gas from air. The separation membrane is the key to the membrane separation method. According to different situations, the technology and materials used are also different. At present, the research and use of separation membrane ${ }^{[3]}$ is still the focus and difficulty of this technology.

\subsection{Condensation method}

Condensation vapor recovery technology uses the physical characteristics of vapors, that is, the liquefaction temperature of volatile organic compounds is higher than that of air, so that hydrocarbon components with high boiling points are separated, thereby achieving the separation of vapor and air. The condensation method oil and gas recovery device adopts multi-stage cascade or self-cascade refrigeration technology, the system process is relatively complicated, and the oil and gas need to be at low temperature to achieve a high recovery rate ${ }^{[5]}$.

Table1. Correspondence between condensation temperature and recovery efficiency

\begin{tabular}{|c|c|c|}
\hline $\begin{array}{c}\text { Condensation } \\
\text { temperature } /{ }^{\circ} \mathbf{C}\end{array}$ & $\begin{array}{c}\text { Rate of } \\
\text { recovery }\end{array}$ & $\begin{array}{c}\text { Exhauste mission } \\
\text { concentration/（g/ } \\
\left.\mathbf{m}^{3}\right)\end{array}$ \\
\hline-40 & $70 \%$ & - \\
\hline-75 & $90 \%$ & $\leq 50$ \\
\hline-95 & $>95 \%$ & $\leq 35$ \\
\hline-110 & $>98 \%$ & $\leq 25$ \\
\hline-120 & $>99 \%$ & $\leq 15$ \\
\hline
\end{tabular}

\subsection{Comparison of oil and gas recovery technologies}




\begin{tabular}{|c|c|c|c|}
\hline & $\begin{array}{l}\text { low concentration, unstable } \\
\text { emission of oil and gas recovery }\end{array}$ & & temperature rise \\
\hline $\begin{array}{l}\text { Condensa } \\
\text { tion } \\
\text { method }\end{array}$ & $\begin{array}{l}\text { It can be directly recovered into } \\
\text { liquid oil, no secondary pollution, } \\
\text { high degree of skid-mounted, } \\
\text { large operating flexibility }\end{array}$ & $\begin{array}{l}\text { High energy consumption, high } \\
\text { installation and operating costs }\end{array}$ & $\begin{array}{l}\text { Optimization of condensing } \\
\text { parameters, waste cooling } \\
\text { recovery, optimization of } \\
\text { equipment structure[6] }\end{array}$ \\
\hline $\begin{array}{l}\text { Membran } \\
\text { e } \\
\text { separatio } \\
\mathrm{n}\end{array}$ & $\begin{array}{l}\text { Low energy consumption, } \\
\text { convenient operation, it can also } \\
\text { remove viruses, bacteria, } \\
\text { macromolecules and inorganic } \\
\text { salts while separating[7] }\end{array}$ & $\begin{array}{l}\text { The membrane performance requirements } \\
\text { are high, domestic technology is not high, } \\
\text { and other oil and gas recovery processes } \\
\text { need to be combined in many places with } \\
\text { large oil and gas volatilization. }\end{array}$ & $\begin{array}{l}\text { Development of high- } \\
\text { performance membrane materials }\end{array}$ \\
\hline
\end{tabular}

Table 3. Comparison of energy consumption of oil and gas recovery technology ${ }^{[8]}$

\begin{tabular}{|c|c|c|c|}
\hline Craft & $\begin{array}{c}\text { Scale } \\
\left(\mathrm{m}^{3} / \mathrm{h}\right)\end{array}$ & $\begin{array}{c}\text { Configure power } \\
(\mathrm{KW})\end{array}$ & $\begin{array}{c}\text { Unit energy consumption } \\
\left(\mathrm{KW} \cdot \mathrm{h} / \mathrm{m}^{3}\right)\end{array}$ \\
\hline Adsorption method & 400 & 120 & 0.30 \\
\hline Absorption method & 950 & 280 & 0.295 \\
\hline Membrane separation & 200 & 50 & 0.25 \\
\hline $\begin{array}{c}\text { Condensation } \\
\text { method }\end{array}$ & 400 & 67 & 0.168 \\
\hline
\end{tabular}

Table 4. Comparison of characteristics of oil and gas recovery process methods

\begin{tabular}{|c|c|c|c|c|}
\hline Method & $\begin{array}{c}\text { Adsorption } \\
\text { method }\end{array}$ & $\begin{array}{c}\text { Absorption } \\
\text { method }\end{array}$ & $\begin{array}{c}\text { Membrane } \\
\text { separation }\end{array}$ & $\begin{array}{c}\text { Condensation } \\
\text { method }\end{array}$ \\
\hline Investment & high & lower & higher & general \\
\hline Operating costs & general & high & higher & low \\
\hline Safety & lower & general & low & higher \\
\hline Equipment area & high & general & higher & low \\
\hline $\begin{array}{c}\text { Maintenance } \\
\text { requirements }\end{array}$ & higher & general & high & low \\
\hline Recovery rate & general & lower & higher & higher \\
\hline
\end{tabular}

\subsection{Combined process}

Different processes have different advantages and disadvantages and different applications. Therefore, the appropriate process should be selected according to the actual situation. For the occasions with strict requirements for oil and gas recovery, it is necessary to select a combined process for oil and gas recovery.

\section{Absorption + membrane separation method}

Ye Mingjun ${ }^{[9]}$ et al. conducted an experimental study on the emission of VOCs from tankers for the hollow fiber membrane absorption method.

This technology combines the absorption method to adapt to high concentration and large flow of VOCs and the low energy consumption

characteristics of membrane separation method.

The research results show that the recovery rate of VOCs discharged from oil tankers can reach $97.5 \%$, and the exhaust gas emission also meets national standards.

Condensation + membrane separation + adsorption method

Condensation + membrane separation + adsorption method ${ }^{[10]}$ The combined process combines the advantages of three single processes. When the oil and gas concentration is high, the condensation method is used, and the membrane separation method is used to remove heavy carbon and moisture in the intermediate stage. The oil and gas concentration is very low. When using adsorption method to recover oil and gas. The recovery rate reaches $99 \%$ and the exhaust gas emission concentration is $\leq 25 \mathrm{~g} / \mathrm{m}^{3}$.

Condensation + adsorption method

Shi $\mathrm{Li}^{[11]}$ conducted simulation and experimental research on the condensation + adsorption combined process. The condensing temperature of the condensing section was designed, and the final oil and gas recovery rate reached $99 \%$, and the outlet oil and gas mass concentration was lower than $7.7 \mathrm{~g} / \mathrm{m}^{3}$. Because the adsorption section is used for low-concentration oil and gas recovery, the heat effect of activated carbon adsorption is reduced and safety is further improved.

Combination process research is the current development trend of oil and gas recovery technology. Through the combination of different oil and gas recovery technologies, the shortcomings of a single process are compensated, the safety of the system and the service life of the equipment are improved, and the ultimate goal is to achieve the recovery rate and meet the exhaust gas emission standards at the same time. Improve economic efficiency. 


\section{VOCs emission reduction technologies for ships at home and abroad}

At present, there are two methods for ships to control VOCs emissions: try to suppress and reduce the generation of oil and gas in the cabin; try to suppress and reduce the generation of oil and gas in the cabin ${ }^{[12]}$.

\subsection{Try to suppress and reduce the generation of oil and gas in the cabin}

Method 1: Design to increase the pressure-bearing capacity of the cabin

The latest large oil tankers in the world achieve the purpose of improving the pressure bearing capacity by improving the bearing strength of the oil bulkhead ${ }^{[13]}$. When the cabin operating pressure reaches a certain value, the production of voc gas can be greatly reduced. The increase in the pressure-bearing capacity of the oil bulkhead will result in an increase in the structural strength of the oil tank. Oil tankers need to install independent $\mathrm{P} / \mathrm{V}$ valves (oil tank pressure/vacuum valves) and $\mathrm{P} / \mathrm{V}$ breaking devices (shared pressure/vacuum breaking devices). It is used to control the oil tank pressure and keep it in a safe range.

Method 2: KVOC technology

$\mathrm{KVOC}^{[14]}$ technology is a patented technology of Norway Knutsen Ship-Ping Company. This technology is used in the cargo oil loading process to effectively suppress the production of voc, and its performance has been reliably verified in the European North Sea. In the traditional oil injection process, cargo oil entering the empty cargo tank through the descending pipeline will cause a sudden pressure drop. It is the pressure sudden drop that causes a large number of vocs. The basic principle of the technology is to reduce the rate of cargo oil entering the tank by increasing the diameter of the descending pipeline, so as to reduce the pressure change when the cargo oil enters the tank, thereby reducing the emission of voc. .

The main design of this method is the diameter design of the downcomer, which is established according to the cargo oil injection rate. In the process of cargo oil loading, KVOC technology can reduce the production of voc by $50 \%$. The advantage is that the design principle is simple and the installation is convenient. However, this technology can only reduce the production of voc during the cargo oil loading process. In the initial stage of cargo oil loading, during the navigation of the ship and the unloading stage, other oil and gas recovery systems are required. The system has been put into use, such as Sallie Knutsen, Tordis Knutsen, Vigdis Knutsen, etc. under the Knutsen shipowner's.

\subsection{Application of oil and gas recovery technology on ships}

CVOC technology (absorption method)
The CVOC technology is designed by GBA Marine. The main principle is to use the hydrostatic pressure of the cargo oil in the cabin during the ship's navigation to absorb the volatilized voc back into the crude oil. VOC emissions can be reduced during sailing and loading, and the system is simple, easy to install, and can be used simultaneously with other emission reduction systems. By 2015, it has been applied on 23 ships, such as DNV class KARENKNUTSEN, GERDKNUTSEN, NAVIONANGLIA, JUANITA, etc.

Absorption + adsorption method

The main principle is to use the adsorption + absorption method at the same time. The main equipment includes activated carbon filter irrigation, vacuum pump and absorption tower device. In actual operation, there are generally two or more adsorption tanks that work alternately. The advantage of the adsorption+absorption method is that it can be recycled, and the recovery rate can reach $92 \%-97 \%$. The disadvantage is that the installation size and weight of the absorption tower are limited, which is difficult to apply. At present, there are not many shuttle tankers equipped with this type of system, and a few are installed such as Navion Europa, Randgrid, Navion Norvegia. At present, the oil and gas recovery technology applied on ships is not mature, and there are problems such as low oil and gas recovery efficiency during ship operation, high operating costs, large equipment size, and self-importance.

\section{Existing problems and suggestions}

\subsection{Improve oil and gas recovery technology}

The principle and performance of oil and gas recovery technology are different, and there are different problems in the actual operation process. It is necessary to conduct a comprehensive analysis of each technology and further improve the oil and gas recovery technology.

It is recommended to continuously reform and develop the oil and gas recovery technology, optimize and improve the oil and gas recovery device, improve the operating efficiency of the equipment, conduct research on the required materials, and further optimize its performance, so as to improve the oil and gas recovery technology. According to the activated carbon adsorption method, the performance of activated carbon materials is studied to improve the service life and adsorption capacity of activated carbon and avoid secondary pollution. For the absorption method, special absorbents are developed. For the condensation method, optimize its process parameters and reduce energy consumption. For the membrane separation method, the main research is high-performance membranes to give play to its advantages of high efficiency and environmental protection.

\subsection{Optimize the oil and gas recovery device}

The correct use of oil and gas recovery technology can improve the efficiency of the oil and gas recovery device, extend its service life, and further ensure its safety. 
However, there are still great restrictions on the use of oil and gas recovery devices on ships. At present, my country has installed oil and gas recovery devices in oil depots and gas stations, but the research and development of marine oil and gas recovery devices has been slow. There is no case of installing oil and gas recovery systems on crude oil carriers in China. The relevant domestic regulations and standards also do not have compulsory requirements and specifications for installing oil and gas recovery and treatment devices on crude oil carriers.

It is recommended that the country introduce relevant domestic and foreign professionals, and refer to GB/T 35579-2017 "General Technical Requirements for Oil and Gas Recovery Devices" to design, manufacture and inspect marine oil and gas recovery devices. Research and optimize the oil and gas recovery device to meet the principles of safe operation, stability, reliability, easy maintenance, and low energy consumption. The design requirements meet three aspects: oil and gas concentration design requirements; device processing capacity design requirements (device scale); structural requirements (reasonable, compact, airtight, complete set). For the absorption method and adsorption method, the focus is on the miniaturization of the core equipment (absorption tower, adsorption tank); for the condensation method, the refrigeration equipment meets the safety requirements and the selection of special refrigerants. In addition, there are various pumps and piping system designs. At the same time, the ship should be equipped with a detection system and a control system.

\section{Conclusion}

In summary, four types of oil and gas recovery technologies are introduced: absorption method, adsorption method, condensation method, and membrane separation method. The advantages and disadvantages and process performance of the four oil and gas recovery technologies are analyzed, and it is pointed out that the combined process can make up for the shortcomings of a single recovery technology, and can meet the recovery rate and emission standards while reducing system energy consumption and prolonging the service life. Listed the actual examples of the current oil and gas recovery technology used by ships, and found its shortcomings. It is recommended to carry out in-depth research from two aspects of improving the oil and gas recovery technology and optimizing the oil and gas recovery device.

\section{References}

1. $\mathrm{Xu}$ Jianhao.Comparative Study on the Safety Standards of the International Maritime Organization, the United States and the Domestic Ship Cargo Vapor Recovery System[J].China Maritime,2020(09):69-72.

2. Jiang Dewen.Analysis on Application of Oil and Gas Recovery Technology in Oil and Gas Storage and Transportation $[\mathrm{J}]$. Chemical Engineering and Equipment, 2018(12):49-50+69.

3. Huang Weiqiu,Wang Danli,Li Feng,Wang
Hongning.Research progress and focus of oil and gas recovery technology[J].Gas Storage and Transportation,2012,31(09):641-646+1.

4. Huang Binwei,Zhang Bin.Research on the Development and Application of Oil and Gas Recovery Technology in Oil and Gas Storage and Transportation $[\mathrm{J}]$.Contemporary Chemical Research, 2019(13):18-19.

5. Miu Zhihua,Zhang Lin,Wang Meng,Zhang Guide,Zhu Zhiping,Wang Tiejun.Technology and Application of Condensation Vapor Recovery[J].Low temperature and superconductivity,2011,39(06):4852.

6. Huang Weiqiu.Several key issues of oil and gas recovery technology[J]. Gas Storage and Transportation, 2017, 36(06):606-616.

7. Cheng Zhigang,Li Hui,Pu Xiaoguang,Wu Kaitao.Application and Research Progress of Oil and Gas Recovery Technology[J].Chemical Engineering and Equipment,2011(12):159-161.

8. Yang Ye. Design and Research of Condensing Oil and Gas Recovery System[D].Hefei University of Technology, 2012.

9. Ye Mingjun,Wang Beifu,Nie Lihong,Lv Jianxiong.Experimental study on the hollow fiber membrane absorption method to recover VOCs discharged from oil tankers[J].Guangzhou Chemical Industry,2017,45(02):70-71.

10. Li Wei,Fang Wei.Application of "Condensation + Membrane Separation + Adsorption" Combined Process in Oil and Gas Recovery[J].Sino-foreign Energy,2016,21(11):93-97.

11. Shi Li,Huang Weiqiu,Hu Zhilun,Cai Daofei,Wang Hongning.Research on the Integrated Recovery Process of Oil and Gas Condensation and Adsorption[J].Acta Petrolei Sinica (Petroleum Processing), 2014,30(01):87-93.

12. Mou Xiaodong.Foreign oil and gas emission control technology and suggestions for large oil tankers[J]. Safety, health and environment, 2015,15(03):1-4.

13. Ye Chaoyang.VOC emission control of crude oil tankers[J].World shipping,2014,37(05):42-45.

14. HJ Rudd, NA Hill. Measures to Reduce Emissions of VOCs during Loading and Unloading of Ships in the $\mathrm{EU}[\mathrm{J}]$. european commission. 